\title{
Influence of social determinants of health on skin to skin contact between mother and newborn
}

\author{
Influência dos determinantes sociais da saúde no contato pele a pele entre mãe e recém-nascido
}

Influencia de los determinantes sociales de la salud en el contacto piel a piel entre la madre y el recién nacido

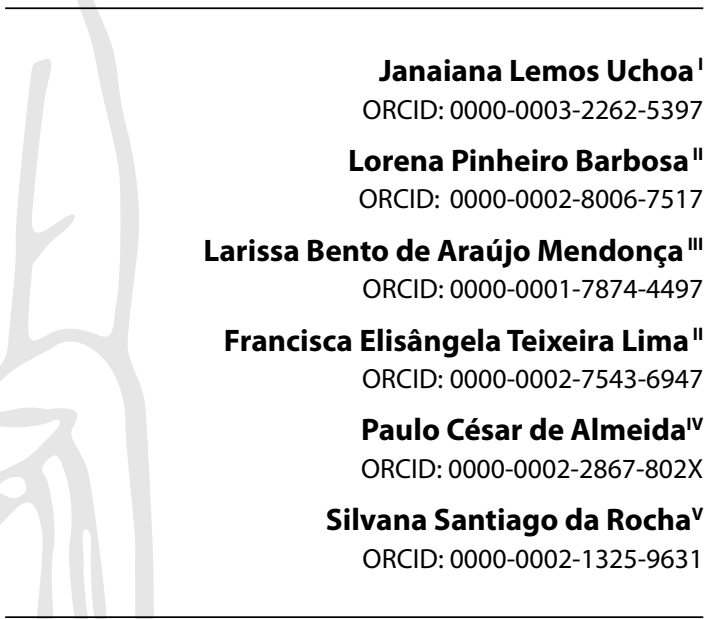

'Universidade Federal do Ceará, Hospital Universitário Walter Cantídio. Fortaleza, Ceará, Brazil. "Universidade Federal do Ceará. Fortaleza, Ceará, Brazil. I" Universidade Federal do Ceará, Maternidade Escola Assis Chateaubriand. Fortaleza, Ceará, Brazil. "Universidade Estadual do Ceará. Fortaleza, Ceará, Brazil. $\checkmark$ Universidade Federal do Piauí. Teresina, Piauí, Brazil.

How to cite this article: Uchoa JL, Barbosa LP, Mendonça LBA, Lima FET Almeida PC, Rocha SS. Influence of social determinants of health on skin to skin contact between mother and newborn. Rev Bras Enferm. 2021;74(Suppl 4):e20200138. https://doi.org/10.1590/0034-7167-2020-0138

Corresponding author: Janaiana Lemos Uchoa janaiana@hotmail.com

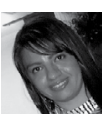

EDITOR IN CHIEF: Antonio José de Almeida Filho ASSOCIATE EDITOR: Hugo Fernandes

\begin{abstract}
Objective: to analyze the association of skin-to-skin contact and social determinants of health. Methods: this is a cross-sectional study with 187 medical records of newborns from a reference rooming in in northeastern Brazil. An instrument with maternal and neonatal data was used. Analysis was descriptive and inferential statistics. For the associations, a chi-square test was used to measure strength, an Odds Ratio was calculated, with a 95\% confidence interval. Results: $62 \%$ of newborns who made skin-to-skin contact at birth were eutrophic, full-term, Apgar $>7$, mothers with prenatal care and without abortion. The determinants associated with non-skin-to-skin contact were preterm ( $C R=3.2 ; 95 \% \mathrm{Cl}: 2.72-18.98) ; 1^{\text {st }}$ minute Apgar < 7 (CR:2.9;95\%Cl: 2.38-3.06), cesarean section (CR:8.4;95\%Cl: 4.29-16.57), and unhealthy NB (CR 12.7;95\%Cl: 4.9-32.67). We used STROBE guidelines. Conclusion: skin-to-skin contact was influenced by gestational age, Apgar, delivery, and newborn health.

Descriptors: Breast Feeding; Maternal-Child Health Services; Social Determinants of Health; Newborn; Public Health Policy.
\end{abstract}

\section{RESUMO}

Objetivo: analisar a associação do contato pele a pele e os Determinantes Sociais da Saúde. Métodos: estudo transversal, com 187 prontuários de recém-nascido do alojamento conjunto de maternidade de referência no nordeste, Brasil. Utilizou-se um instrumento com dados maternos e neonatais. A análise foi estatística descritiva e inferencial. Para as associações, usou-se teste qui-quadrado, para medir a força, calculou-se Razão de Chance, com intervalo de confiança a $95 \%$. Resultados: $62 \%$ dos recém-nascidos que fizeram contato pele a pele ao nascer eram eutróficos, a termo, Apgar $>7$, mães com pré-natal e sem aborto. Os determinantes associados com a não realização do contato pele a pele: pré-termo ( $\mathrm{RC}=3,2 ; \mathrm{IC} 95 \%: 2,72-18,98)$, Apgar $1^{\circ}$ minuto < 7 (RC:2,9;IC95\%: 2,38-3,06), cesárea (RC:8,4;IC95\%: 4,29-16,57) e RN não saudável (RC 12,7;IC95\%: 4,9-32,67). Sob diretrizes do STROBE. Conclusão: o contato pele a pele foi influenciado por variáveis dos determinantes: idade gestacional, Apgar, parto e a saúde do recém-nascido.

Descritores: Aleitamento Materno; Saúde Materno-Infantil; Determinantes Sociais da Saúde; Recém-Nascido; Políticas Públicas de Saúde.

\section{RESUMEN}

Objetivo: analizar la asociación del contacto piel con piel y los determinantes sociales de la salud. Métodos: estudio transversal con 187 registros médicos de recién nacidos de la sala de maternidad de referencia en el Nordeste, Brasil. Se utilizó un instrumento con datos maternos y neonatales. Para las asociaciones, se usó una prueba de chi-cuadrado para medir la fuerza y se calculó el Odds Ratio. Resultados: $62 \%$ de los recién nacidos que hicieron contacto piel con piel al nacer eran eutróficos, a término, Apgar $>7$, madres con atención prenatal y $\sin$ aborto. Determinantes asociados: prematuro ( $C R=3.2 ;$ IC 95\%: 2.72-18.98); Apgar $1^{\circ}$ minuto <7 (RC: 2.9; IC 95\%: 2.38-3.06); cesárea (CR: 8.4; IC 95\%: 4.29-16.57) y recién nacido no saludable (CR 12.7; IC 95\%: 4.9-32.67). Bajo las pautas STROBE. Conclusión: el contacto piel con piel fue influenciado por variables determinantes: edad gestacional, Apgar, parto y la salud del recién nacido.

Descriptores: Lactancia; Salud Materno-Infantil; Determinantes Sociales de la Salud; Recién Nacido; Políticas Públicas de Salud. 


\section{INTRODUCTION}

Baby-Friendly Hospital Initiative (BFHI), proposed by the World Health Organization (WHO) and the United Nations Children's Fund (UNICEF) in 1990, established in Brazil in 1992, aims to promote, protect and support breastfeeding (BF) through the Ten Steps to Successful Breastfeeding ${ }^{(1)}$. The fourth step consisted of mothers starting BF in the first half hour of life through skin-to-skin contact (SSC) of mothers with their babies immediately (five minutes postpartum for at least one hour) ${ }^{(1)}$, but was revised in 2018, and advises facilitating immediate (up to the first two hours of life) and uninterrupted (for 60 minutes), supporting BF as soon as possible after birth, i.e., $\mathrm{BF}$ in the first hour of life is a consequence of $\mathrm{SSC}^{(2)}$.

The Brazilian National Policy for Comprehensive Child Health Care (Política Nacional de Atenção Integral à Saúde da Criança), established in 2015 in Brazil $^{(3)}$, aims to promote and protect children's health and BF. Despite the existence of strategies to promote BF, it is perceived that in practice, SSC is not yet being properly implemented in BFHI, according to a meta-analysis study conducted in 2016, in which it was identified that only $50 \%$ of newborns (NB) are breastfed during the first hour of life ${ }^{(4)}$.

There is scientific evidence that early and immediate SSC favors NB thermoregulation, cardiorespiratory stabilization and glycemic levels and reduction of stress caused by birth and is associated with longer duration of $\mathrm{BF}^{(5)}$, peaceful sleep and decreased perception during invasive procedures ${ }^{(6)}$, promoting tranquility ${ }^{(7)}$. In mothers, SSC increases the release of catecholamines, improves the interaction and bond between mother and $\mathrm{NB}^{(5)}$ through the biochemical activation of the reward circuits of the brain of both $^{(8)}$, strengthens physiological and emotional stability, reduces the potential for pain, increases the satisfaction of mothers and significantly improves milk production ${ }^{(6)}$.

The increase in time and early onset of BF in the first hour of life is a result of successful implementation of the fourth step of $\mathrm{BFHI}$ and has been evidenced in studies ${ }^{(9)}$. However, it is noticed that the sociodemographic characteristics and living conditions of pregnant women (social determinants of health - SDH) can influence the implementation of SSC and of $\mathrm{BF}^{(10)}$.

A study developed in Australia concluded that the main reasons for 17,564 mothers to stop exclusive breastfeeding (EBF) up to six months were age under 20 years, smoking, partner violence and lack of support ${ }^{(11)}$. This evidences the need to analyze women's SDH in the pregnancy-puerperal cycle to know which are modifiable $\mathrm{SDH}$ s that can influence SSC and, consequently, BF.

$\mathrm{SDH}$ are social, economic, cultural, ethnic, racial, psychological and behavioral factors that can influence the occurrence of health problems in the population. To control these factors, it is necessary to know them so that measures can be taken to circumvent such factors. There are several models of social determination of health. In this study, we chose to use the Dahlgren and Whitehead model due to simplicity and graphic clarity.

In this model, five layers ${ }^{(12)}$ of influence on health are approached, describing the social ecological theory for health that maps the relationship between individual, environment, and disease. In Layer two, modifiable variables are considered, depending on the lifestyle of individuals to macropolitical, economic, cultural, and social issues ${ }^{(12)}$. Brazil has expanded this definition by the
Brazilian National Commission of Social Determinants of Health (CNDSS - Comissão Nacional de Determinantes Sociais da Saúde), including "social, economic, cultural, ethnic/racial, psychological and behavioral factors that influence the occurrence of health problems and their population of risk factors" ${ }^{\prime \prime(13)}$.

In Layer 1, there are individual determinants, generally nonmodifiable, such as age, gender, and genetic inheritance. In Layer 2 , there are proximal or microdeterminant determinants that are individual behaviors and lifestyles. In Layer 3, the influence of social and community relations stands out. In Layer 4, intermediate determinants such as living and working conditions, food availability, access to essential environments and services such as health, education, sanitation and housing are represented. Finally, in Layer 5, there are the distal macrodeterminants that are the economic, cultural and environmental conditions of society, in addition to supranational determinants such as globalization ${ }^{(12)}$.

It is understood that the identification and analysis of modifiable SDH constitute strategies for policy formulation and health care aimed at the proper implementation of BFHI in Brazilian public hospitals, highlighting SSC in the first two hours of life considering scientific evidence of short- and long-term benefits for mothers and NB. SSC, the fourth item of the Ten Steps to Successful Breastfeeding is still little explored, and studies associated with $\mathrm{SDH}$ are nonexistent, which justifies the importance of this study.

All professionals who work in the delivery room are responsible for SSC, such as nursing professionals. They are responsible for being facilitators, especially in providing information and assisting in SSC and BF management in the delivery room. Nurses have the possibility of encouraging other health professionals present in birth care regarding awareness-raising and intervention of modifiable $\mathrm{SDH}$, information and integration to the program of incentive, promotion and support to SSC and BF in the first hour of life. To achieve this goal it is necessary to acquire scientific knowledge, technical skill, and joint communication ${ }^{(14)}$.

\section{OBJECTIVE}

To analyze whether there is an association between non-performance of skin-to-skin contact in the delivery room with the variables of the social determinants of health layers of mothers and infants.

\section{METHODS}

\section{Ethical aspects}

The research obtained a favorable opinion from the institution's Research Ethics Committee via Brazil platform, respecting Resolution 466/12 of the Brazilian National Health Council (Conselho Nacional de Saúde).

\section{Study design, period, and location}

This is an observational, cross-sectional, descriptive, retrospective, quantitative study. For the construction of this study, the guidelines and recommendations of the STrengthening the Reporting of OBservational studies in Epidemiology (STROBE) were followed. 
Data collection was performed by the researchers in a roomingin (RI) at a tertiary care maternity in the capital of northeastern Brazil. BFHI received the Dr. Pinotti- Amigo da Mulher Hospital award in 2019 by the Chamber of Deputies in Brasilia, being a Sentinel Hospital by the Brazilian Health Regulatory Agency (ANVISA - Agência Nacional de Vigilância Sanitária) since 2006 and is recognized by the Ministry of Health (MoH) since 2016 as a Support Center for Good Practices in Obstetrics and Neonatology. The collection period was in June 2017, because one month of delivery in this maternity school meets the sample calculation, in which there is a large volume of deliveries. In 2016, there were 5,163 deliveries. In the first four months of 2017 , there were 1,572 deliveries, with an average of 393 monthly deliveries. During data collection, the secondary sources consulted were NBs' medical records and May 2017 unit admission book records.

\section{Population and sample; inclusion and exclusion criteria}

The sample calculation was of the entire population using 219 medical records of NBs admitted to RI in May 2017, with 5\% margin of error and confidence level of $95 \%$, totaling a sample of 140 medical records; however, the researchers chose to compose the sample with the entire population, i.e., for all 219 medical records. Thus, the eligibility criteria adopted were medical records containing NBs' records in the delivery room filled out by a neonatologist containing the record of good obstetrics and neonatology practices, including SSC and BF performance in the first hour of life. Medical records of NBs with HIV-positive mothers, unable to breastfeed $(n=2)$ and NB who were transferred from RI to the Conventional Neonatal Intermediate Care Unit (CoNICU) due to clinical complications $(n=10)$ or hospital discharge $(n=20)$ whose medical records were not available in RI during data collection were excluded. Therefore, after the sample losses $(n=32)$, the sample consisted of 187 medical records of NBs, with a sampling error of $5 \%$. There was no sampling bias.

\section{Study protocol}

The information was extracted from NBs' medical records and from Rl's admission book, using an instrument of own elaboration, validated by two specialists in the field, and a pilot test was performed in five medical records of NBs admitted in June 2017, which did not comprise the sample. Data were categorized by variables according to Dahlgren and Whitehead's model ${ }^{(12)}$, arranged in four layers: Layer 1 - Mother: age, NB: birth weight, gestational age classification (GA) and $1^{\text {st }}$ minute Apgar; Layer 2 - Mother: education and marital status; Layer 3 - Mother: number of children; Layer 4 - Mother: prenatal care, number of consultations, childbirth type, gestational history, parity and abortion, NB: health at birth.

Healthy newborns were considered those who did not need to go to a Neonatal Intensive Care Unit (NICU) or a CoNICU or a Kangaroo Neonatal Intermediate Care Unit (KaNICU). In the latter, NBs weighing more than $1,000 \mathrm{~g}$ are treated, stable, without central venous access, in full enteral nutrition, for clinical followup and weight gain, or with discharge from NICU, but still needs complementary care, with mild respiratory distress, however, still needing complementary care, with mild respiratory distress, but which do not need mechanical ventilation or NB submitted to medium-sized surgery, stable, after the immediate postoperative period in NICU ${ }^{(15)}$. The SSC's routine in maternity, in all its units, is recommended by the Ten Steps to Successful Breastfeeding.

\section{Analysis of results, and statistics}

Due to the lack of national literature on SSC and SDH, international studies on SSC or BF were used in the discussion, because this is a consequence of SSC, because in this study NBs who did not undergo SSC in their mothers were excluded, thus, they were not in BF.

A descriptive and inferential statistical analysis was performed. The data obtained were organized in a spreadsheet in Microsoft Excel through double typing and subsequent validation, in order to control possible errors. They were exported and processed by the Software Statistical Package for Science Social (SPSS), version 20.0, license number 10101131007 and presented in tables, with absolute and relative frequencies, in addition to the means and standard deviations of quantitative variables. To check the association between the variable of interest, SSC only between mothers and newborns and the independent variables, some SDH present in the medical records, the chi-square test was applied. The strength of the associations was calculated by Odds Ratio (OR) and 95\% confidence interval $(\mathrm{Cl})$, these being considered statistically significant if $p<0.05$.

\section{RESULTS}

Table 1 presents SDH in: Layer 1 - individual determinants; Layer 2 - proximal determinants or microdeterminants; Layer 3 - influence of social and community relations; and Layer 4 intermediate determinants, both versus not performing CPP between mother and NB.

According to Table 1, among the $62 \%$ NBs who had SSC immediately at birth with their mother, it was found, in individual determinants, that $39.6 \%$ of mothers were between 20 and 34 years old; $57.8 \%$ of NBs weighed from 2,500 to $3,999 \mathrm{~g} ; 58.8 \%$ were fullterm; and $62 \%$ were born with $1^{\text {st }}$ minute Apgar from seven to nine.

Regarding proximal determinants, $33.7 \%$ of mothers completed high school; $49.7 \%$ were married or had a common-law marriage. In the influence layer of social relations, $28.3 \%$ of puerperal women reported not having had other children, i.e., the current NB, at the time of the research, was the first living child.

In the intermediate determinants, $61 \%$ of the mothers had prenatal care; $49.7 \%$ had six to 14 prenatal consultations; $49.7 \%$ had vaginal delivery; $35.3 \%$ multi-gestas; $33.7 \%$ multiparous; $51.9 \%$ had no history of abortions; and $58.8 \%$ of the nb were admitted directly to the delivery room.

According to Table 2, there was a statistical significance between SSC non-performance between mother-NB and SDH, being influenced by $\mathrm{SDH}$ : weight of $\mathrm{NB}<2,500 \mathrm{~g}(\mathrm{CR}=3.2 ; \mathrm{Cl}$ : 1.04-10.11, p: 0.034), preterm GA classification ( $C R=7.2 ; \mathrm{Cl}: 2.72-$ $18.98, \mathrm{p}<0.001), 1^{\text {st }}$ minute Apgar between three and six $(C R=2.9$; Cl: 2.38-3.06 p<0.001), cesarean section ( $C R=8.4$; $C l$ : 4.29-16.57, $\mathrm{p}<0.001)$ and NB who at birth needed complementary care and went to a CoNICU (CR=12.7; $\mathrm{Cl}$ : 4.9-32.67, $\mathrm{p}<0.001)$. 
Table 1 - Dahlgren's and Whitehead's layers of social determinants of health and skin-to-skin contact between mother and newborn in a tertiary maternity, Fortaleza, Ceará, Brazil, 2017

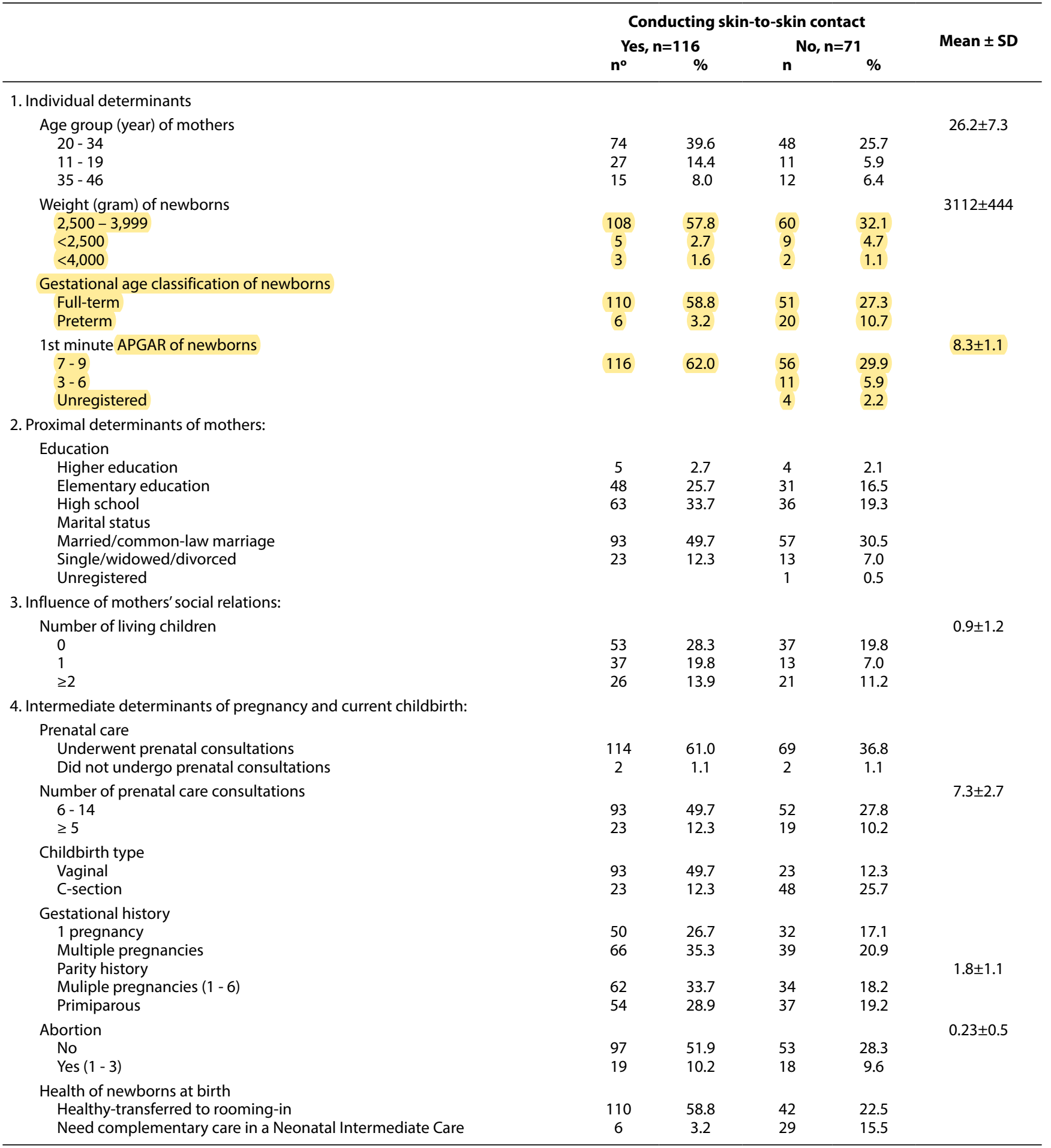

Even though it was not statistically significant with the other layers of $\mathrm{SDH}$, it was possible to verify in Layer 1 that maternal age from 35 to 46 years increased the risk by twice as much as NBs did not perform SSC. In Layer 2, mothers with higher education were 1.4 times more likely not to perform SSC.

In Layer 3, it was observed that mothers without children or with two or more living children were 2 and 2.3 times more likely not to perform SSC. In Layer 4, mothers who did not have prenatal care or with less than six consultations or had a history of abortion presented, respectively, 1.7, 1.5 and 1.7 more chances of not having SSC soon after the birth of a NB.

The association of the power of SDH with non-SSC in the delivery room was evident in preterm infants with $1^{\text {st }}$ minute Apgar $<7$, both of the $1^{\text {st }}$ layer of the non-modifiable individual determinants; and cesarean section and unhealthy NB at birth, both of the $4^{\text {th }}$ layer of intermediate determinants of health services. 
Table 2 - Analysis of the power of association between non-skin-to-skin contact in the delivery room and social determinants of health in a tertiary maternity, Fortaleza, Ceará, Brazil, 2017

\begin{tabular}{|c|c|c|c|c|}
\hline \multirow{2}{*}{ 1. Individual determinants } & \multirow[t]{2}{*}{$\mathbf{R C}$} & \multicolumn{2}{|c|}{$(95 \%) \mathrm{Cl}$} & \multirow[t]{2}{*}{$\rho$} \\
\hline \multirow{2}{*}{\multicolumn{5}{|c|}{ Age group (year) of mothers }} \\
\hline & & & & \\
\hline $20-34$ & 1 & & & \\
\hline $11-19$ & 1.6 & 0.72 & 3.51 & 0.246 \\
\hline $35-46$ & 2.0 & 0.70 & -5.52 & 0.198 \\
\hline \multicolumn{5}{|l|}{ Weight (gram) of newborns } \\
\hline $2,500-3,999$ & 1 & & & \\
\hline$<2,500$ & 3.2 & 1.04 & -10.11 & 0.034 \\
\hline$<4,000$ & 1.2 & 0.20 & -7.38 & 0.845 \\
\hline \multicolumn{5}{|l|}{ Gestational age classification of newborns } \\
\hline Full-term & 1 & & & \\
\hline Preterm & 7.2 & 2.72 & 18.98 & $<0.001$ \\
\hline \multicolumn{5}{|l|}{ 1st minute APGAR of newborns } \\
\hline $7-9$ & 1 & & & \\
\hline $3-6$ & 2.9 & 2.38 & -3.06 & $<0.001$ \\
\hline \multicolumn{5}{|l|}{ 2. Proximal determinants of mothers } \\
\hline \multicolumn{5}{|l|}{ Education } \\
\hline High education & 1 & & & \\
\hline Elementary education & 1.1 & 0.61 & -2.08 & 0.694 \\
\hline Higher education & 1.4 & 0.35 & -5.55 & 0.631 \\
\hline \multicolumn{5}{|l|}{ Marital status } \\
\hline Single/widowed/divorced & 1 & & & \\
\hline Married/common-law marriage & 1.1 & 0.51 & -2.31 & 0.834 \\
\hline \multicolumn{5}{|l|}{ 3. Influence of mothers' social relations } \\
\hline \multicolumn{5}{|l|}{ Number of living children } \\
\hline 0 & 2.0 & 0.93 & -4.24 & 0.074 \\
\hline 1 & 1 & & & \\
\hline$\geq 2$ & 2.3 & 0.98 & -5.40 & 0.054 \\
\hline \multicolumn{5}{|l|}{ 4. Intermediate determinants of pregnancy and current childbirth } \\
\hline \multicolumn{5}{|l|}{ Prenatal care } \\
\hline Underwent prenatal consultations & 1 & & & \\
\hline Did not undergo prenatal consultations & 1.7 & 0.22 & 11.99 & 0.616 \\
\hline \multicolumn{5}{|l|}{ Number of prenatal care consultations } \\
\hline $6-14$ & 1 & & & \\
\hline$\geq 5$ & 1.5 & 0.73 & -2.96 & 0.270 \\
\hline \multicolumn{5}{|l|}{ Childbirth type } \\
\hline Vaginal & 1 & & & \\
\hline C-section & 8.4 & 4.29 & 16.57 & $<0.001$ \\
\hline \multicolumn{5}{|l|}{ Abortion } \\
\hline No & 1 & & & \\
\hline Yes $(1-3)$ & 1.7 & 0.96 & -4.48 & 0.060 \\
\hline \multicolumn{5}{|l|}{ Health of newborns at birth } \\
\hline Healthy-transferred to rooming-in & 1 & & & \\
\hline Need complementary care in Neonatal Intermediate Care & 12.7 & 4.90 & 32.67 & $<0.001$ \\
\hline
\end{tabular}

Note: *Pearson's chi-square; *Likelihood ratio.

\section{DISCUSSION}

Immediate and uninterrupted SSC for at least one hour is among the most effective strategies for promoting $\mathrm{EBF}^{(16)}$. Thus, studies on SDH are fundamental to know their association with practice of SSC. In national and international literature, there were studies in which there was a statistical association in SSC performance with improvement in EBF rates, compared to mothers and NBs who were not submitted to SSC soon after delivery ${ }^{(17)}$.

With practice of SSC shortly after birth, it can be observed, in relation to individual determinants, that mothers over 20 years old were more likely not to perform SSC. Studies in Nigeria, Bangladesh, Italy and 24 other countries (seven from Africa, eight from Latin America and nine from Asia) observed that mothers over 35 years old are less likely to breastfeed their newborns ${ }^{(18-19)}$ and to have SSC shortly after delivery ${ }^{(18)}$, compared to younger mothers. A similar result was found in a Brazilian metropolis, with 12,283 mothers, adolescents are more likely to perform SSC than other age groups. Not performing SSC was higher in mothers aged 40 years or older ${ }^{(5,10)}$. However, studies have shown that younger mothers, when compared to older mothers, have a higher risk of early interruption of EBF, probably due to mothers'low educational level, lower purchasing power and because they are single $\mathrm{e}^{(20)}$.

A study conducted in south-western Sydney, with 1,035 NB mothers, found that there was no association between maternal age and the onset of $\mathrm{BF}^{(21)}$. The effect of advanced age with success of BF is not yet clarified; however, in the last 20 years, there are records of an increase in maternal age in the first delivery in most developed countries ${ }^{(22)}$. In general, mothers of advanced age are more likely to start BF and maintain it longer ${ }^{(23)}$, contrasting 
the findings of our study. It is noteworthy that although the first layer is considered non-modifiable for SSC, becoming pregnant or having a young birth may be a reflection of poor family planning policies, formal education and the encouragement of early sexual initiation in recent years and that these SDHs for pregnancy, childbirth and abortion in this age group can be modifiable with quality public policies.

Regarding birth weight, NB with low weight had a 3.2 times greater chance of not undergoing SSC, corroborating a study developed in Valencia, Spain, with 1,071 NBs, in which it was found that low birth weight $(<2,500 \mathrm{~g})$ contributes as a determining factor for the interruption of EBF up to the age of six months ${ }^{(24)}$.

A study in a Brazilian metropolis reveals that NBs with adequate weight and full-term had, respectively, 23 and 18 times greater chance of performing SSC ${ }^{(10)}$; this is due to the fact that, in general, preterm NBs present clinical instabilities at birth, making it impossible to perform SSC, considering that they need immediate care for stabilization, otherwise they may present complications in the hospital and evolve to death.

In developed countries, SSC is considered technology in the kangaroo method and can be used for long or short periods in less stable NB and by both parents. However, this method has not yet been associated with a reduction in neonatal mortality, although data are currently insufficient to determine an effect ${ }^{(25)}$.

In neonatology, efforts have been made to improve the care of premature NBs and there are several methods used to reduce the stress to which these NBs are subjected during hospitalization. In this perspective, SSC can also be practiced in neonatal inpatient units, both by the mother and the father, in order to alleviate the suffering to which these NB are subjected, in addition to promoting the proactive involvement of parents and the strengthening of bonds ${ }^{(26)}$.

Studies with premature infants admitted to NICU found that SSC reduces maternal anxiety, postpartum depression, facilitating lactation ${ }^{(27)}$, increasing the incidence of EBF, improving weight gain, promoting early hospital discharge ${ }^{(25)}$, facilitating $B F$ in very premature $\mathrm{NB}^{(28)}$, reducing parental stress, promoting motherchild interaction ${ }^{(25)}$ and increasing the bond ${ }^{(5)}$, BF and parents' self-esteem ${ }^{(6)}$. Despite the verified benefits, it is known that there is an underutilization of continuous SSC in NICUs, and this practice is not implemented as it should (26-27).

Regarding the Apgar score, NB with a score less than 7 had a higher CR of not having SSC, which can be justified by their clinical instability at birth. Corroborating our study, a survey, carried out in another maternity hospital, in 2018, found that the Apgar score in the first minute influenced the initiation of early BF in the group of women undergoing vaginal delivery; however, further investigation is suggested to determine the reasons why Apgar does not influence the early BF of NB born by cesarean section ${ }^{(1)}$.

In Layer 2, the proximal determinants, arising from behaviors and lifestyles, mothers with higher education had a greater chance of not undergoing SSC. In contrast, a cohort study conducted in southwest Sydney, in public maternity hospitals, with 935 puerperal women, found that higher levels of education and maternal occupational status were associated with an increased chance of starting $\mathrm{BF}$, while being a single mother it was associated with a decreased chance of starting early $\mathrm{BF}^{(21)}$. In contrast to the study above, a randomized clinical trial, carried out in Iran, with 68 pregnant women, showed that education, number of pregnancies and abortions did not influence SSC ${ }^{(29)}$. In Brazil, in a study with more than 12 thousand medical records, the SDH for the did not carry out prevalent SSC were mothers who have high education, paid profession, married, using drugs, multiple pregnancy, complications in childbirth. SSC was much more prevalent in illiterate ${ }^{(10)}$.

In Layer 3, social relations, it was observed that mothers who had no live children or had two or more children had a greater chance of not undergoing SSC after delivery. A survey in Bangladesh found that mothers with two to three children were significantly more likely to have SSC compared to mothers with up to one child or more than three children. Still in the same study, it was found that, in Nigeria, the early onset of BF was significantly associated with parity, as mothers with two to three children had a $23 \%$ increase in the chances of SSC compared to mothers with only one child ${ }^{(18)}$.

It is emphasized that mothers with other children are more likely to perform SSC and maintain EBF, mainly because they have had previous experiences, 1.07 times more chance of $\mathrm{SSC}^{(10)}$ in favor of $\mathrm{BF}^{(30)}$.

In Layer 4 of the $\mathrm{SDH}$, even though there was no association between prenatal care (PN) and SSC, it was found that most mothers adhered to what is recommended by the $\mathrm{MoH}$ in Brazil in relation to the minimum number of six PN consultations ${ }^{(31)}$. A research carried out in 2016 in a milk bank, with 12,823 records of mothers attended between 2009 and 2012, with the objective of identifying factors involved in the performance of SSC, attested that undergoing PN, with at least six consultations, favored 1, 5 times more chance of SSC. Being positively associated with the prevalence of $\mathrm{EBF}^{(10)}$, SSC was performed more often among those who received guidance on $\mathrm{BF}$ in $\mathrm{PN}^{(5,10)}$ and about the importance of $\mathrm{BF}$ in the first hour of life $(p=0.007)^{(32)}$. It is signaled that access to $P N$ can be influenced by other SDH, including local individual and structural conditions, mainly access to the health unit, such as transportation ${ }^{(33)}$.

Childbirth type is a reflection of the assistance provided to puerperal women in the health networks and can considerably influence SSC. In the present study, puerperal women who underwent cesarean section did less SSC than those who underwent vaginal delivery, corroborating a study in northeastern Brazil, which assessed the ten steps of BF and that failure to perform SSC was associated with cesarean delivery $(p<0.01)^{(32)}$. In another study in a Brazilian metropolis, during vaginal delivery, there was 34 times more chance of having SSC when compared to cesarean sections and forceps ${ }^{(10)}$. Such findings are consistent with other studies, in which it was identified that cesarean section is related to the late onset of $\mathrm{BF}^{(24,31)}$. However, it is known that, after cesarean, immediate SSC can be performed normally, in the case of spinal or epidural block, considering that mother and NB remain alert and responsive ${ }^{(34)}$.

Furthermore, the benefits of immediate SSC after cesarean section were verified, based on a systematic review, such as mothers physiological stability and NB, emotional well-being, improved communication skills, potential to reduce maternal pain and promote early onset of $\mathrm{BF}^{(35)}$. In a qualitative study, carried out in a public maternity hospital in southern Brazil with midwifery health professionals, in the statements it is mentioned that, in SSC in post-cesarean section implantation, difficulties in puerperal 
women were observed, such as nausea after anesthesia; for NB, greater risk of falling; from the institution and health professionals, NBs during SSC would hinder the care of the puerperal woman and would need a larger space for the post-cesarean care and circulation of the professionals and the temperature of the air conditioning different for the professionals and the puerperal woman. As facilitating factors for SSC, it was reported that PN was performed at the same birth institution, the presence of a companion and training of health professionals ${ }^{(36)}$.

It is pointed out that the percentage of cesarean deliveries in the studied institution is high, if compared with the rate acceptable by the WHO (10-15\%)(37); however, this is due to the fact that motherhood is a tertiary reference, serving high-risk pregnant women from all over the state.

Regarding parity, the majority of multiparous women performed SSC, in line with studies that demonstrated that multiparous women have better adherence to EBF than primiparous women ${ }^{(20)}$, being associated with an increased probability of early $\mathrm{BF}^{(33)}$, contrasting a study carried out in a Brazilian metropolis, that there was a greater number of SSC in primiparous mothers ${ }^{(10)}$.

In a prospective, observational, single-center study in a nursery in Milan, Italy, with 640 NB, it was found that previous (vicarious) maternal experiences are related to parity, and if the previous experience is negative, the mother is unlikely to breastfeed, compared to first-time mothers ${ }^{(19)}$. It has also been reported that vicarious experience can direct inexperienced mothers to BF and get help from other mothers with positive experience, allowing them to have a role model ${ }^{(30)}$. It is believed that abortion, as it is a maternal consternation, may hinder the mother's bond with the new NB, making SSC more difficult.

There was a predominance of SSC in mothers with no previous history of abortion, and the same finding was found in a randomized clinical trial in Iran, with 96 NB mothers (38 in routine and 38 in SSC $)^{(8)}$. However, in Brazil, a longitudinal study with 50 NB conducted in the northeast and in primary care found that there was no positive correlation between the abortion rate of women with the effectiveness of $\mathrm{BF}^{(30)}$.

Neonates from CoNICU have a 12.7 times greater chance of not undergoing SSC, compared to those admitted to the delivery room. This fact can be explained by the maternal and birth conditions of NBs, as the need for hospitalization in CONICU is justified by maternal or neonatal clinical complications, making it impossible to perform SSC.

Highlighting the importance of SSC in stabilizing NB, a study of 2,841 NB, carried out in a maternity hospital in the southwestern United States, two years before the implementation of SSC during cesarean section (2011-2012) ( $n=1,070$ NB) and three years after the implementation of SSC during cesarean section (2013-2015) ( $n=1,771 \mathrm{NB}$ ), showed a significant reduction in the proportion of NBs admitted to NICU after implementation of SSC after cesarean section. Thus, it is concluded that one of the beneficial effects for these NBs was the clinical stabilization ${ }^{(38)}$.

A Cochrane review points out that there is evidence for SSC to promote $\mathrm{BF}$, however studies with large sample sizes are needed to confirm the benefits of this intervention on the physiology of NB during their transition to extrauterine life to establish possible doseresponse effects and the ideal time for your initiation. It should also be noted that the methodological quality of studies on SSC remains a problem, as the benefits of SSC for NBs are limited due to the fact that randomized clinical studies (RCTs) are small, reporting different outcomes, measured at different scales and with limited data ${ }^{(7)}$.

In a northeastern BFHI in Brazil, the low compliance with the fourth stage of BF was found, and the nursing team and pediatricians were the main responsible for implementing $\mathrm{SSC}^{(32)}$. There is a strong tendency, in the current decade, to promote health policies that address SDH, defined as the social characteristics that occur individually or due to social conditions. These definitions express the intention to address the causes of diseases, health inequalities and social conditions that affect health. In the present study, we analyzed SSC. It is important to study them to promote specific measures related to SDH, such as income, education, occupation, family structure and health. The quality of the availability of public services is offered: hygiene, minimizing the risk of disease, occupation, family structure, social networks and support, social discrimination and access to preventive health actions ${ }^{(39)}$. Thus, it is important to devise strategies that modify SDH related to not performing SSC in the delivery room.

\section{Study limitations}

Layer 5, the last of SDH, represented by the economic, cultural, environmental and political conditions in force in the country for the mother ${ }^{(12)}$, was not documented in NBs delivery room record or in the birth book record, RI admission (family allowance or other social projects and socio-economic condition), making collection impossible, constituting an important limitation of this research. Secondary data also limited the need to specify the exact duration of SSC right after delivery, since, in the delivery room record, it only informs whether SSC was performed or not. In this study, it was considered that SSC happened during the first two hours of life, that is, immediately after delivery, as recommended by the $\mathrm{BFHI}$ reformulated in 2018. In addition, there are countless social policies to encourage $B F$, such as the right to maternity leave and $\mathrm{BFHI}$, implemented and implemented in health institutions, both with a significantly positive impact on the success of $\mathrm{SSC}$ and $\mathrm{BF}^{(33)}$.

\section{Contributions to nursing, health, and public policies}

The SDH study is favorable for measuring the effectiveness of the strategies of the Brazilian National Policy for Comprehensive Child Health Care, with a view to greater PN coverage with guidelines on $\mathrm{SSC}^{(5)}$ and $\mathrm{BF}$, to favor SSC and promotion of BF by all health professionals, especially nurses, who work with health care, promotion and education, directly in the management of NP, childbirth, postpartum, puerperium, childcare and family planning at the three levels of health care. health, in one of the $\mathrm{MoH}$ programs: Kangaroo Method ${ }^{(40)}$, Humanization of Prenatal and Birth $^{(41)}$, qualification of neonatal care ${ }^{(42)}$ and qualified discharge from $\mathrm{NBs}^{(43)}$. SSC is an important instrument for establishing the mother-child bond, although it is still little explored by professionals and pregnant women. This situation can result from misinformation about the right to breastfeed and SSC in the delivery room. Thus, $\mathrm{PN}$ is an ideal occasion for the dissemination of such practices ${ }^{(5)}$.Such misinformation could justify the negative 
relationship between SSC in the delivery room and older women, multiparous, with few or no PN consultations.

SSC in the delivery room can also be influenced by strict health services norms and routines, little investment in training and institutional tradition ${ }^{(44)}$, which are macro-determinants of DDS, i.e., Baby-Friendly Hospitals that are still did not reach wide dissemination and/or implementation of the ten steps of $\mathrm{BF}^{(5)}$. Studies of this nature are pertinent to understand the context of pregnant women who seek care in Basic Health Units and hospitals. Thus, the interventions, considering $\mathrm{SDH}$, must be worked on for more effective realization of SSC.

\section{CONCLUSIONS}

The results of this research allow inferring an association with statistical significance of the following SDH with SSC: classification of gestational age, $1^{\text {st }}$ minute Apgar score, childbirth type and health conditions of NBs at birth. In this perspective, nurses must have knowledge about the impact of SDH in the performance of SSC, as they can execute national strategies of assistance to childbirth and children, such as the kangaroo method, Humanization of Prenatal and Birth, qualification of neonatal care and qualified discharge NB to promote such practice in Brazilian maternity hospitals.

Finally, the importance of providing guidance during the prenatal period about SSC and BF in the first hours of life is highlighted, as recommended by $\mathrm{BFHI}$, aiming to sensitize this clientele about the benefits of such practice for the mother and NB to short and long term. It is suggested that longitudinal researches be carried out, following the moment of delivery until the interruption of SSC. It is also evident the need for more research on the subject, in view of the scarce literature found on the association of SDH with SSC.

\section{REFERENCES}

1. Lau Y, Tha PH, Ho-Lim SST, Wong LY, Lim PI, Citra Nurfarah BZM, et al. An analysis of the effects of intrapartum factors, neonatal characteristics, and skin-to-skin contact on early breastfeeding initiation. Matern Child Nutr. 2018;14(1):e12492. https://doi.org/10.1111/mcn.12492

2. World Health Organization (WHO). UNICEF. Implementation guidance: protecting, promoting and supporting breastfeeding in facilities providing maternity and newborn services: the revised Baby-Friendly Hospital Initiative. Geneva: WHO; 2018. 56 p.

3. Ministério da Saúde (BR). Resolução no 1,130, agosto, 05, 2015. Institutes the National Policy for Comprehensive Child Health Care (PNAISC) within the scope of the Unified Health System (SUS). Brasil: Diário Oficial da União; Aug 6, 2015.

4. Victora CG, Bahl R, Barros AJDD, França GVAA, Horton S, Krasevec J, et al. Breastfeeding in the 21st century: epidemiology, mechanisms, and lifelong effect. Lancet. 2016;387(10017):475-90. https://doi.org/10.1016/S0140-6736(15)01024-7

5. Silva CME, Pellegrinelli ALR, Pereira SCL, Passos IR, Santos LC, Silva CM, et al. Educational practices in accordance with the "Ten steps to successful breastfeeding" in a Human Milk Bank. Ciênc Saúde Colet. 2017;22(5):1661-71. https://doi.org/10.1590/1413-81232017225.14442015

6. Baley J, Committee on fetus and newborn. Skin-to-Skin care for term and preterm infants in the neonatal ICU. Pediatrics. 2015;136(3):596-9. https://doi.org/10.1542/peds.2015-2335

7. Moore ER, Bergman N, Anderson GC. Early skin-to-skin contact for mothers and their healthy newborn infants. Cochrane Database Syst Rev. 2016;11(11):CD003519. https://doi.org/10.1002/14651858.CD003519.pub4

8. Beiranvand S, Valizadeh F, Hosseinabadi R, Pournia Y. The Effects of Skin-to-Skin Contact on Temperature and Breastfeeding Successfulness in Full-Term Newborns after Cesarean Delivery. Int J Pediatr. 2014;2014:846486. https://doi.org/10.1155/2014/846486

9. Vittner D, McGrath J, Robinson JA, Lawhon G, Cusson R, Eisenfeld L, et al. Increase in Oxytocin From Skin-to-Skin Contact Enhances Development of Parent-Infant Relationship. Biol Res Nurs. 2018;20(1):54-62. https://doi.org/10.1177/1099800417735633

10. Silva CM, Pereira SCL, Passos IR, Santos LC. Factors associated with skin to skin contact between mother/son and breastfeeding in the delivery room. Rev Nutr. 2016;29(4):457-71. https://doi.org/10.1590/1678-98652016000400002

11. Ogbo FA, Eastwood J, Page A, Arora A, McKenzie A, Jalaludin B, et al. Prevalence and determinants of cessation of exclusive breastfeeding in the early postnatal period in Sydney, Australia. Int Breastfeed J. 2017;12(1). https://doi.org/10.1186/s13006-017-0110-4

12. Dahlgren $G$, Whitehead M. Policies and strategies to promote social equity in health: background document to WHO - Strategy paper for Europe [Internet]. Vol. 14, Institute for futures studies. 2007 [cited 2018 Sep 17]. 67 p. Available from: https://core.ac.uk/download/pdf/6472456.pdf

13. Buss PM, Pellegrini Filho A. Health and its social determinants. Physis. 2007;17(1):77-93. https://doi.org/10.1590/s0103-73312007000100006

14. Silva JLP, Linhares FMP, Barros AA, Souza AG, Alves DS, Andrade PON, et al. Factors associated with breastfeeding in the first hour of life in a baby-friendly hospital. Texto Contexto Enferm. 2018;27(4):4190017. https://doi.org/10.1590/0104-07072018004190017

15. Machado LG. Fatores associados à transferência de recém-nascidos elegíveis para a unidade de cuidados intermediários canguru em maternidades brasileiras [Dissertação] [Internet]. Rio de Janeiro. Fundação Oswaldo Cruz; 2017 [cited 2018 Aug 2]. Available from: https:// www.arca.fiocruz.br/bitstream/icict/25228/2/luiza_machado_iff_mest_2017.pdf

16. Crenshaw JT. Healthy Birth Practice \#6: Keep Mother and Baby Together: it's best for mother, baby, and breastfeeding. J Perinat Educ. 2014;23(4):211-7. https://doi.org/10.1891/1058-1243.23.4.211.

17. Guala A, Boscardini L, Visentin R, Angellotti P, Grugni L, Barbaglia M, et al. Skin-to-Skin contact in cesarean birth and duration of breastfeeding: a cohort study. Sci World J. 2017;2017:1-5. https://doi.org/10.1155/2017/1940756 
18. Singh K, Khan SM, Carvajal-Aguirre L, Brodish P, Amouzou A, Moran A. The importance of skin-to-skin contact for early initiation of breastfeeding in Nigeria and Bangladesh. J Glob Health. 2017;7(2). https://doi.org/10.7189/jogh.07.020505

19. Colombo L, Crippa BL, Consonni D, Bettinelli ME, Agosti V, Mangino G, et al. Breastfeeding determinants in healthy term newborns. Nutrients. 2018;10 (1):48. https://doi.org/10.3390/nu10010048

20. Sipsma HL, Jones K, Nickel NC. Hospital practices to promote breastfeeding: the effect of maternal age. Birth. 2017;44(3):272-80. https://doi. org/10.1111/birt.12284

21. Arora A, Manohar N, Hayen A, Bhole S, Eastwood J, Levy S, et al. Determinants of breastfeeding initiation among mothers in Sydney, Australia: findings from a birth cohort study. Int Breastfeed J. 2017;12:39. https://doi.org/10.1186/s13006-017-0130-0

22. Kitano N, Nomura K, Kido M, Murakami K, Ohkubo T, Ueno M, et al. Combined effects of maternal age and parity on successful initiation of exclusive breastfeeding. Prev Med Reports. 2016;3:121-6. https://doi.org/10.1016/j.pmedr.2015.12.010

23. Tarrant M, Fong DY, Wu KM, Lee IL, Wong EM, Sham A, et al. Breastfeeding and weaning practices among Hong Kong mothers: a prospective study. BMC Pregnancy Childbirth. 2010;10(1):27. https://doi.org/10.1186/1471-2393-10-27

24. Vila-Candel R, Duke K, Soriano-Vidal FJ, Castro-Sánchez E. Effect of early skin-to-skin mother-infant contact in the maintenance of exclusive breastfeeding: experience in a health department in Spain. J Hum Lact. 2018;34(2):304-12. https://doi.org/10.1177/0890334416676469

25. Conde-Agudelo A, Díaz-Rossello JL. Kangaroo mother care to reduce morbidity and mortality in low birthweight infants. Conde-Agudelo A, (Ed.). Cochrane Database Syst Rev. 2016;(8):CD002771. https://doi.org/10.1002/14651858.CD002771.pub4

26. Angelhoff C, Blomqvist YT, Sahlén Helmer C, Olsson E, Shorey S, Frostell A, et al. Effect of skin-to-skin contact on parents' sleep quality, mood, parent-infant interaction and cortisol concentrations in neonatal care units: study protocol of a randomised controlled trial. BMJ Open. 2018;8(7):e021606. https://doi.org/10.1136/bmjopen-2018-021606

27. Stikes R, Barbier D. Applying the plan-do-study-act model to increase the use of kangaroo care. J Nurs Manag. 2013;21(1):70-8. https://doi. org/10.1111/jonm.12021

28. Nyqvist KH, Rosenblad A, Volgsten H, Funkquist E-L, Mattsson E. Early skin-to-skin contact between healthy late preterm infants and their parents: an observational cohort study. Peer J. 2017;5:e3949. https://doi.org/10.7717/peerj.3949

29. Adeli M, Aradmehr M. A comparative study of maternal-neonate abdominal and kangaroo (skin-to-skin) skin contact immediately after birth on maternal attachment behaviors up to 2 months. J Educ Health Promot. 2018;7:42. https://doi.org/10.4103/jehp.jehp_46_16

30. Uchoa JL, Gomes AL, Joventino ES, Oriá MOB, Ximenes LB, Almeida PC, et al. Sociodemographic and obstetric history in maternal selfefficacy in nursing: a study in panel. O Braz J Nurs. 2014;13(4). https://doi.org/10.5935/1676-4285.20144708

31. Uchoa JL, Peripolli RA, Joventino ES, De APC, Oria MOB, Ximenes LB. The self-efficacy in breastfeeding of women in the prenatal and postpartum: longitudinal study. Rev Enferm UFSM. 2016;6(1). https://doi.org/10.5902/2179769217687

32. Sampaio ÁRR, Bousquat A, Barros C. Skin-to-skin contact at birth: a challenge for promoting breastfeeding in a "Baby Friendly" public maternity hospital in northeast Brazil. Epidemiol Serv Saude. 2016 Jun;25(2):281-90. https://doi.org/10.5123/S1679-49742016000200007

33. Kim D, Saada A. The social determinants of infant mortality and birth outcomes in western developed nations: a cross-country systematic review. Int J Environ Res Public Health. 2013;10(6):2296-335. https://doi.org/10.3390/ijerph10062296

34. World Health Organization (WHO). UNICEF, Wellstart International. Section 1, Background and implementation. Produced. In: Baby-friendly hospital initiative : revised, updated and expanded for integrated care. Geneva:WHO; 2009. p. 80. Available from: https://apps.who.int/iris/ bitstream/handle/10665/43593/9789241594967_eng.pdf?sequence=1

35. Stevens J, Schmied V, Burns E, Dahlen H. Immediate or early skin-to-skin contact after a Caesarean section: a review of the literature. Matern Child Nutr. 2014;10(4):456-73. https://doi.org/10.1111/mcn.12128

36. Kologeski TK, Strapasson MR, Schneider V, Renosto JM. Skin to skin contact of the newborn with its mother in the perspective of the multiprofessional team. Rev Enferm UFPE[Internet]. 2017 [cited 2019 Nov 2];11(1):94-101. Available from: https://periodicos.ufpe.br/ revistas/revistaenfermagem/article/download/11882/14341

37. World Health Organization (WHO). HRP. WHO Statement on Caesarean Section Rates [Internet]. Geneva, Switzerland; 2015 [cited 2019 Jun 14]. Available from: https://apps.who.int/iris/bitstream/handle/10665/161442/WHO_RHR_15.02_eng.pdf?sequence=1

38. Schneider LW, Crenshaw JT, Gilder RE. Influence of immediate skin-to-skin contact during cesarean surgery on rate of transfer of newborns to NICU for observation. Nurs Womens Health [Internet]. 2017;21(1):28-33. https://doi.org/10.1016/J.NWH.2016.12.008

39. Geib LTC. Social determinants of health in the elderly. Ciênc Saude Colet. 2012;17(1):123-33. https://doi.org/10.1590/S1413-81232012000100015

40. Ministério da Saúde (BR). Resolução no 1,683, of jul 12, 2007. Approves, in the form of the Annex, the Guidelines for the Implementation of the Kangaroo Method. Brasil: Diário Oficial da União; n o 134.

41. Ministério da Saúde (BR). Resolução no 569, of jun 01, 2000. Establish the Humanization Program in Prenatal and Birth, within the scope of the Unified Health System. Brasil: Diário Oficial da União; Jun 8, 2000 p. 4-6.

42. Ministério da Saúde (MS). Resolução no 3,389, of dec 30, 2013. Amends, adds and revokes provisions of Ordinance no. 930/GM/MS, of may 10,2012 , which defines the guidelines and objectives for the organization of comprehensive and humanized care for serious or potentially serio. Brasil: Diário Oficial da União; Dec 31, 2013 p. 54. 
43. Ministério da Saúde (BR). Resolução no 2,068, of oct 21, 2016. Institutes guidelines for the organization of comprehensive and humanized care for women and newborns in Joint Housing. 204 Brasília, Brasil: Diário Oficial da União; 2016 p. 120.

44. Boccolini CS, Carvalho ML, Oliveira MIC. Factors associated with exclusive breastfeeding in the first six months of life in Brazil: a systematic review. Rev Saude Publica. 2015;49:91. https://doi.org/10.1590/S0034-8910.2015049005971 